\title{
Biodegradation of starch blended polyvinyl chloride films by isolated Phanerochaete chrysosporium PV1
}

\author{
M. I. Ali $\cdot$ S. Ahmed $\cdot$ I. Javed $\cdot$ N. Ali . \\ N. Atiq · A. Hameed $\cdot$ G. Robson
}

Received: 23 July 2012/Revised: 11 February 2013/Accepted: 23 February 2013/Published online: 26 March 2013

(C) Islamic Azad University (IAU) 2013

\begin{abstract}
The accumulation of plastics in the environment is raising great concerns with respect to long-term environmental, economic and waste management problems. The aim of the present research was to investigate the biodegradability of starch blended polyvinyl chloride films in soil burial and controlled laboratory experiments using selective fungal isolates. Clear surface aberrations as color change and minor disintegration in polyvinyl chloride films were observed after 90 days and later confirmed through scanning electron microscopy. The fungal strains showing prominent growth and adherence on plastic films were isolated. One of the strains showing maximum activity was selected and identified as Phanerochaete chrysosporium PV1 by rDNA sequencing. Fourier transform infrared spectroscopy and nuclear magnetic resonance analyses indicated considerable structural changes and transformation in films in terms of appearance of new peaks at $3,077 \mathrm{~cm}^{-1}$ (corresponding to alkenes) and decrease in intensity of peaks at $2,911 \mathrm{~cm}^{-1}(\mathrm{C}-\mathrm{H}$ stretching). It was supported with a significant decrease in the molecular weight of polymer film from 80,275 to $78,866 \mathrm{Da}$ (treated) through Gel permeation chromatography in shake flask experiment. Moreover, the biodegradation of starch
\end{abstract}

M. I. Ali $(\bowtie) \cdot$ S. Ahmed $\cdot$ N. Ali · N. Atiq · A. Hameed

Department of Microbiology, Quaid-i-Azam University, Islamabad, Pakistan

e-mail: ishi_ali@hotmail.com

I. Javed

Department of Dairy Technology, University of Veterinary and

Animal Sciences Lahore, Lahore, Pakistan

G. Robson

Faculty of Life Sciences, University of Manchester,

Manchester, UK blended polyvinyl chloride films was confirmed through release of higher $\mathrm{CO}_{2}(7.85 \mathrm{~g} / \mathrm{l})$ compared to control $(2.32 \mathrm{~g} / \mathrm{l})$ in respirometric method. So fungal strain $P$. chrysosporium PV1 has great potential for use in bioremediation of plastic waste.

Keywords Biodegradation - Fungal isolate - Soil burial · Fourier transform infrared spectroscopy .

Scanning electron microscopy

\section{Introduction}

Polyvinyl chloride (PVC) is the third most widely produced plastic due to its wide range of application and its durability, however, it is very rigid and persistent polymer (UNEP 2009) with extremely slow rate of degradation in the environment (Shah et al. 2008a, b). Mostly physical and chemical methods are used for the degradation and recycling of the PVC. Besides, during reduction in size of the PVC containing waste, it produces gases like $\mathrm{CO}_{2}$, furans and dioxins which not only increase the environmental pollution but also reported as carcinogenic and causes diseases of the skin and the respiratory tract (US EPA 2005). Various plasticizers including di-octyl adipate (DOA), di-octyl phthalate (DOP) and Bis(2-ethylhexyl) phthalate (DEHP) are usually added to PVC. Addition of these plasticizers improves the flexibility, processability and extensibility of the PVC products (Wojciechowska 2012). Besides, it facilitates microbial growth when PVC products are disposed into the environment (Nair et al. 2009), thereby solving the issue of environmental pollution (Webb et al. 1999; Gumargalieva et al. 1999; Wojciechowska 2012).

Biodegradation is a process by which microorganisms transform or break down the structure of chemicals 
compounds through metabolic or enzymatic action. Currently, both bacteria and fungi have considerably been labeled for their ability to degrade plastics (Gu et al. 2000). Most biodegradation studies of plastics have been focused on polyurethanes (Kay et al. 1991; Barratt et al. 2003), bacterial polyesters (Mergaert et al. 1996) and nylon (Deguchi et al. 1997); however, few studies have also been reported on the biodegradation of pPVC degradation in situ (Upsher and Roseblade 1984; Webb et al. 2000; Sabev et al. 2006). Partial degradation of PVC by white rot fungus under high oxygenic condition is also reported (Kirbas et al. 1999). The polymer degradation can be enhanced by the addition of certain other additives including cellulose, plasticizers, etc. (Kaczmarek and Bajer 2007; Ali et al. 2009). It has also been reported that starch can be used in the composite material to increase the degradability of the synthetic polymer (Bikiaris et al. 1999). Polyvinyl alcohol (PVA) has excellent compatibility with starch and such blends have been developed and tested for biodegradable packaging applications and appear to have potential for use (Tudorachi et al. 2000). Adhesion of Aureobasidium pullulans has been shown to be dependent on the chemical composition of the PVC and more precisely related to the presence of plasticizers such as DOA and DOP (Webb et al. 2000). Generally, a single technique has never been effective in knowing the comprehensive degradation of plastic, so a combination of different techniques should always been used to assess the biodegradation of plastics. Scanning electron microscopy has been one of the basic tools to assess the physical changes and deterioration within the plastics. However, detailed chemical transformations have been effectively proved by techniques like FTIR, NMR and GPC (Kaczmarek and Bajer 2007).
Owing to the wide range of applications for pPVC, a detailed understanding of degradation process and the role of potential microorganisms are of much importance in the environmental perspective. Therefore, the current research work was designed to isolate microorganisms from the soil with the potential to adhere and degrade polyvinyl chloride films blended with starch. Besides, this investigation involves applications of a variety of analytical techniques like SEM, FTIR, GPC and NMR which could really help in establishing better understanding on the biodegradation of starch blended PVC by selective microorganisms.

\section{Materials and methods}

\section{Casting of starch blended polyvinyl chloride films}

Casting of polyvinyl chloride films blended with starch were carried out in petri plates by taking PVC and starch $2 \%(\mathrm{w} / \mathrm{v})$ in chloroform. The mixture was sonicated for $2 \mathrm{~h}$ in an ultrasonic water bath $(35 \mathrm{kHz}, 285 \mathrm{~W})$, and left overnight to dry. The films $(6 \times 2.5 \mathrm{~cm})(0.05-0.07 \mathrm{~mm}$ thickness) were sterilized by dipping into $70 \%$ ethanol for 20 min (Calil et al. 2006).

\section{Isolation screening and identification} of microorganisms

Starch blended PVC film degrading microorganisms were screened out in soil burial experiment and shake flask experiment. Thin films of starch blended PVC film were buried in the garden soil inoculated with the sewage sludge for a period of 3 months. The films were taken out and shifted to the Sabouraud dextrose agar plates and incubated
Fig. 1 Starch blended PVC films after 3 months soil burial experiment

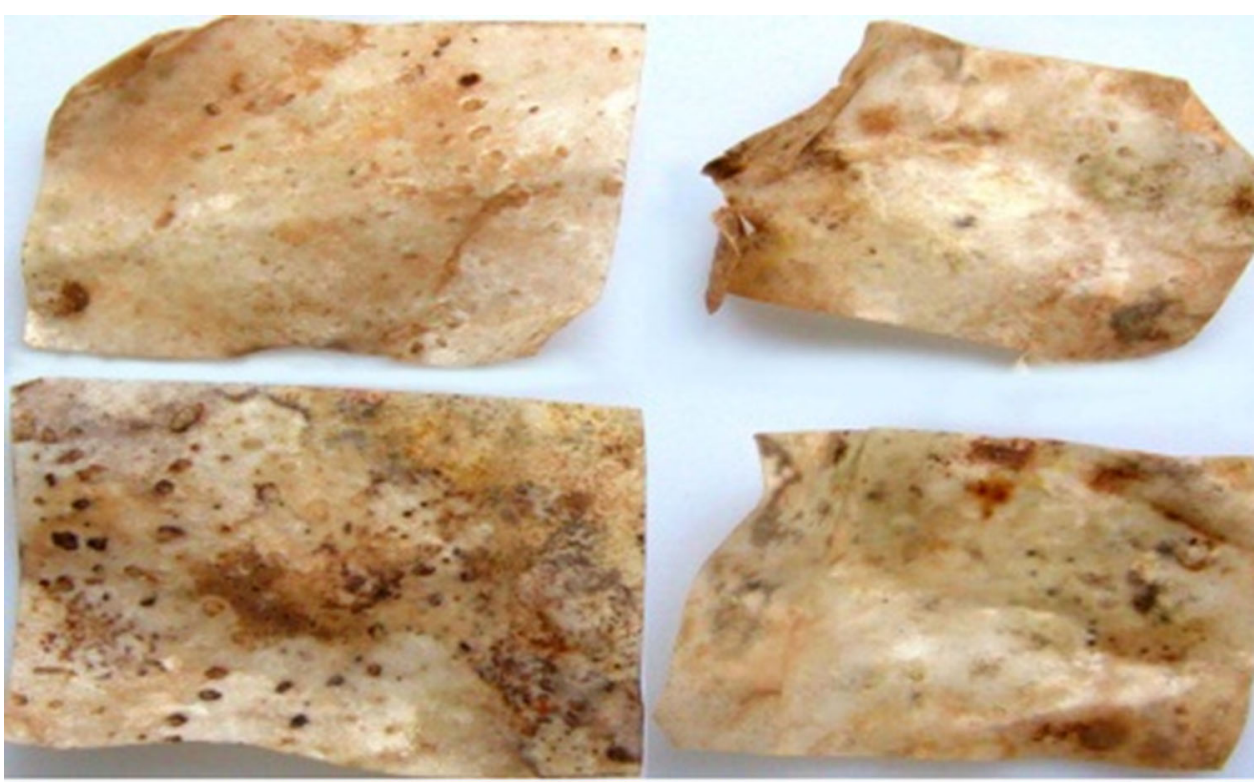



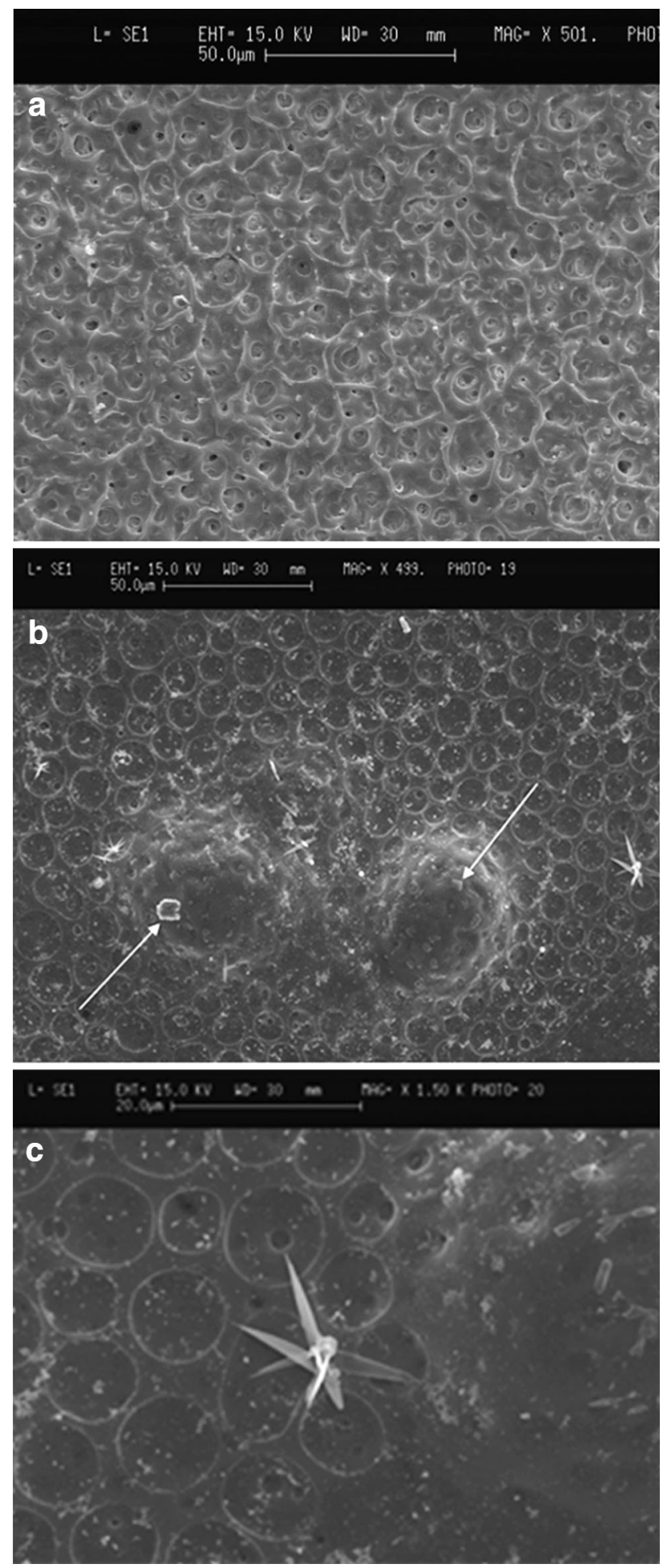

Fig. 2 Scanning electron micrographs of the starch blended polyvinyl chloride films. a Untreated film, b, c after 3 months shake flask experiment with Phanerochaete chrysosporium PV1

at $30{ }^{\circ} \mathrm{C}$. The fungal isolates were inoculated in $150 \mathrm{ml}$ of mineral salt media (MSM) in conical flasks with starch blended PVC films to each flask except the control. All the treatments were incubated in an incubator shaker at $150 \mathrm{rpm}$ for 12 weeks at $30^{\circ} \mathrm{C}$. Biomass quantification was performed for the screening and selection of the fungal isolates having potential to adhere and degrade starch blended PVC films in shake flask experiment. The fungal isolates from soil were cultured in $250 \mathrm{ml}$ Pyrex flask containing $100 \mathrm{~mL}$ MSM, with starch blended PVC film as a sole carbon source, in shaking incubator at $155 \mathrm{rpm}$ at $30{ }^{\circ} \mathrm{C}$. The quantification was done on weekly basis (Christensen et al. 1995).

Fungal isolates were identified by PCR amplification and partial sequencing of the internally transcribed spacer (ITS) regions of 5.8S rRNA, $18 \mathrm{~S}$ and $28 \mathrm{~S}$ rRNA using the fungal universal primers ITS-1 5'-TCCGTAGGT GAACCTGCGG- $3^{\prime}$ and ITS-4 $5^{\prime}$-TCCTCCGCTTATTG ATATGC- $3^{\prime}$ as previously described (Webb et al. 1999). PCR was performed using $50 \mu \mathrm{l}$ of reaction mixture containing $\sim 100 \mathrm{ng}$ of genomic DNA $\left(20 \mathrm{ng}^{-1} \mathrm{l}^{-1}\right)$. The final concentration of components in the PCR was $1 \times$ PCR buffer $\left(160 \mathrm{mM}\left(\mathrm{NH}_{4}\right) 2 \mathrm{SO}_{4}, 670 \mathrm{mM}\right.$ Tris- $\mathrm{HCl}, \mathrm{pH} 8.8$ and $0.1 \%$ stabilizer), $1.5 \mathrm{mM} \mathrm{MgCl} 2,0.02 \mathrm{mM}$ of ITS- 1 and ITS-4 primers (Eurofins, UK), $0.2 \mathrm{mM}$ of dNTPs (Bioline, UK) and $0.5 \mathrm{U}$ of Taq DNA polymerase (Bioline, UK). The PCR was carried out under the following conditions: denaturation at $95{ }^{\circ} \mathrm{C}$ for $1 \mathrm{~min}$, followed by annealing at $55^{\circ} \mathrm{C}$ for $1 \mathrm{~min}$ for 40 cycles and finally extension at $72{ }^{\circ} \mathrm{C}$ for $1 \mathrm{~min}$. Sequence data were aligned with sequences available at GenBank databases (Ali et al. 2012).

\section{Analysis of biodegradation}

The biodegradability of the starch blended PVC films in soil burial experiment and shake flask experiment was determined by SEM (Cambridge instruments, Cambridge, UK) to observe the surface changes. The change in the molecular weight of starch blended PVC films was determined by GPC made by Viscotek GPC max VE 2001 (Texas) equipped with the refractometric (Shoedex RI-71) and viscometric (Viscotek, Model T50A) detectors. Two connected columns (GMHHR-MS type, TSK-GEL) were used with tetrahydrofuran as mobile phase. The calibration was performed using the polystyrene standard. Fourier transform infrared spectroscopy (FTX 3000 MX Bio Rad, USA) (detection limit $400-4,500 \mathrm{~cm}^{-1}$ ) was used to observe changes in the chemical structure of the polymer. The starch blended PVC films were dissolved in the solvent (Chloroform $\mathrm{CDCl}_{3}$ ) and then they were analyzed in the Bruker 400MHZ NMR spectrophotometer. The biodegradation of the polymers results in the evolution of $\mathrm{CO}_{2}$ (by the oxidation of the polymer chains). The carbon dioxide evolved was determined gravimetrically by Sturm test (Muller et al. 1992; Shah et al. 2008a, b). 


\section{Results and discussion}

Visual observation

Soil burial experiments were carried out to check the biodegradability of starch blended PVC films under terrestrial conditions. In these experiments, clear signs of surface aberrations were noticed in terms of color change and alterations in the physical structure of the starch blended PVC films (Fig. 1). Similar experimental set up was run previously in different studies where they reported considerably changes in the physical properties of the treated pPVC films during soil burial conditions (Ohtaki et al. 1998). These changes were apparently linked with microbial growth on film (biofilm), specifically due to fungal hyphae (Tuominen et al. 2002; Sabev et al. 2006; Shah et al. 2008a, b).

Surface examination of polyvinyl chloride starch blended films through SEM showed erosions and extensive roughening on the top surface in comparison to control (untreated PVC starch blend film) (Fig. 2). The Cracks in the films were infested with microbial growth. Such colonization and adhesion by microorganisms are a fundamental prerequisite for biodegradation of the polymer. The polymer films showed clear surface erosion, cracks, holes and initiation points, indicating that the polymer has become brittle due to Phanerochaete chrysosporium PV1 activity in shake flask (150 rpm) experiments for 12 weeks at $30{ }^{\circ} \mathrm{C}$ (Fig. 2). These observations are substantially in line with the observations made in other studies where they treated cellulose blended PVC with cellulolytic fungi like Trichocladium sp. and Chaetomium sp. (Calil et al. 2006;
Kaczmarek and Bajer 2007). de Campos et al. (2011) also reported the PVC film in the soil showed some cavities, cracks, and fungal hyphae adhering to its surface. Incorporation of starch into plastics not only changed its mechanical properties, but also made the plastic susceptible to microorganism (Fanta et al. 1992; Imam et al. 1995; Kirbas et al. 1999).

Screening and identification of fungal isolate

The fungal biomass was quantified on a weekly basis during 7-week incubation period in shake flask experiments. The maximum growth, i.e., $0.316 \mathrm{~g} / 100 \mathrm{ml}$, was observed in case of fungal strain PV1, followed by PV3 (0.18 g/100 ml), PV2 (0.176 g/100 ml) and PV4 (0.130 g/ $100 \mathrm{ml}$ ) (Fig. 3). So, the fungal strain PV1 was selected for the further experiments on the basis of its growth and adhering capability. The fungal strain PV1 was identified by rDNA sequencing. Sequences were compared to sequences held at the NCBI using FASTA and on the basis of its $99 \%$ taxonomic homology it is identified as $P$. chrysosporium PV1 Accession no. EU543990 (Ali et al. 2012). Webb et al. (2000) employed similar method of rDNA sequencing for identification purpose for the selected microorganism capable of clearing plasticizer agar and recovered in high numbers.

Analysis by Sturm test

Sturm test (ASTM D5209-91) was commonly employed for evaluation of the biodegradability of polymer materials.
Fig. 3 The growth of fungal isolates in mineral salt medium with PVC starch blends as sole carbon source

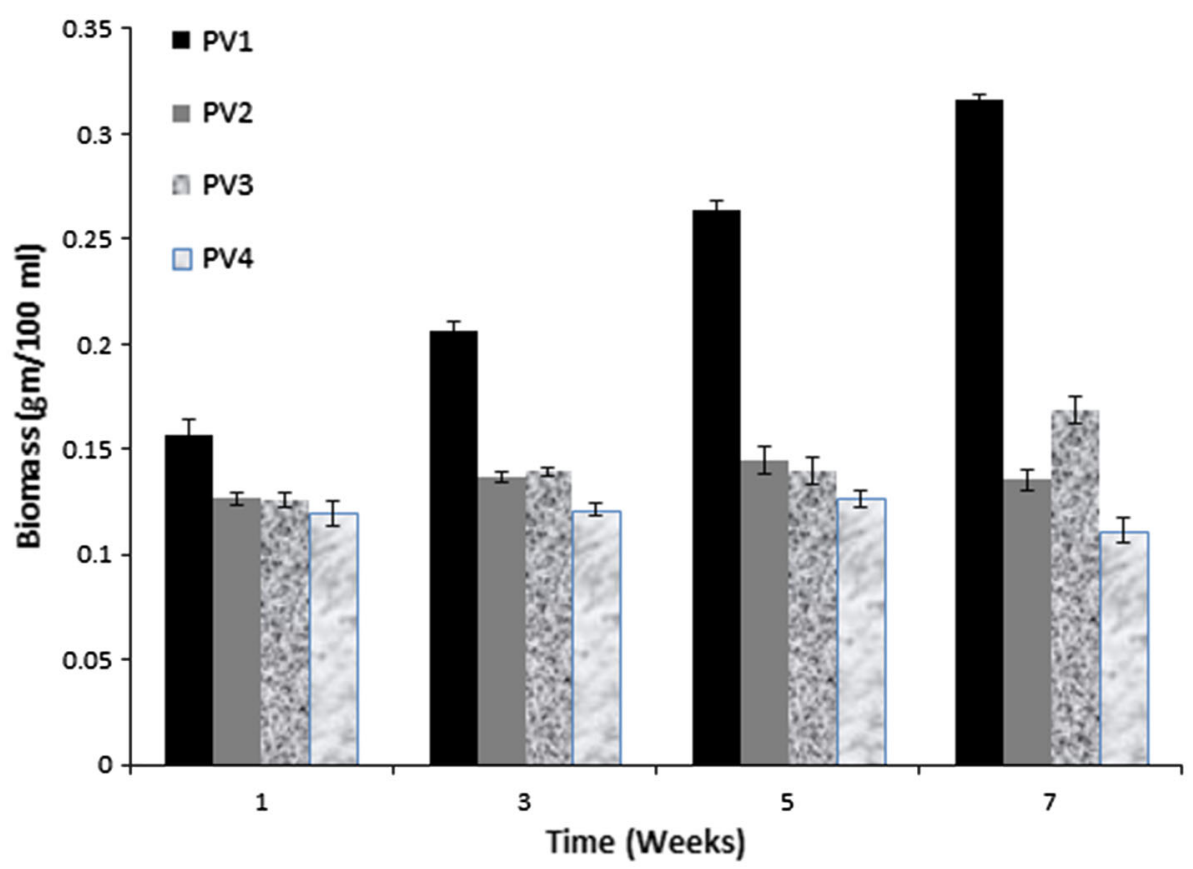


Fig. 4 Dry cell mass and gravimetric analysis of $\mathrm{CO}_{2}$ evolution during breakdown of starch blended polyvinyl chloride films treated with Phanerochaete chrysosporium PV1 determined through Sturm test after 4 weeks

Fig. 5 Fourier transforms infrared spectra of starch blended polyvinyl chloride films, a control, b after 3 months shake flask experiment with Phanerochaete chrysosporium PV1
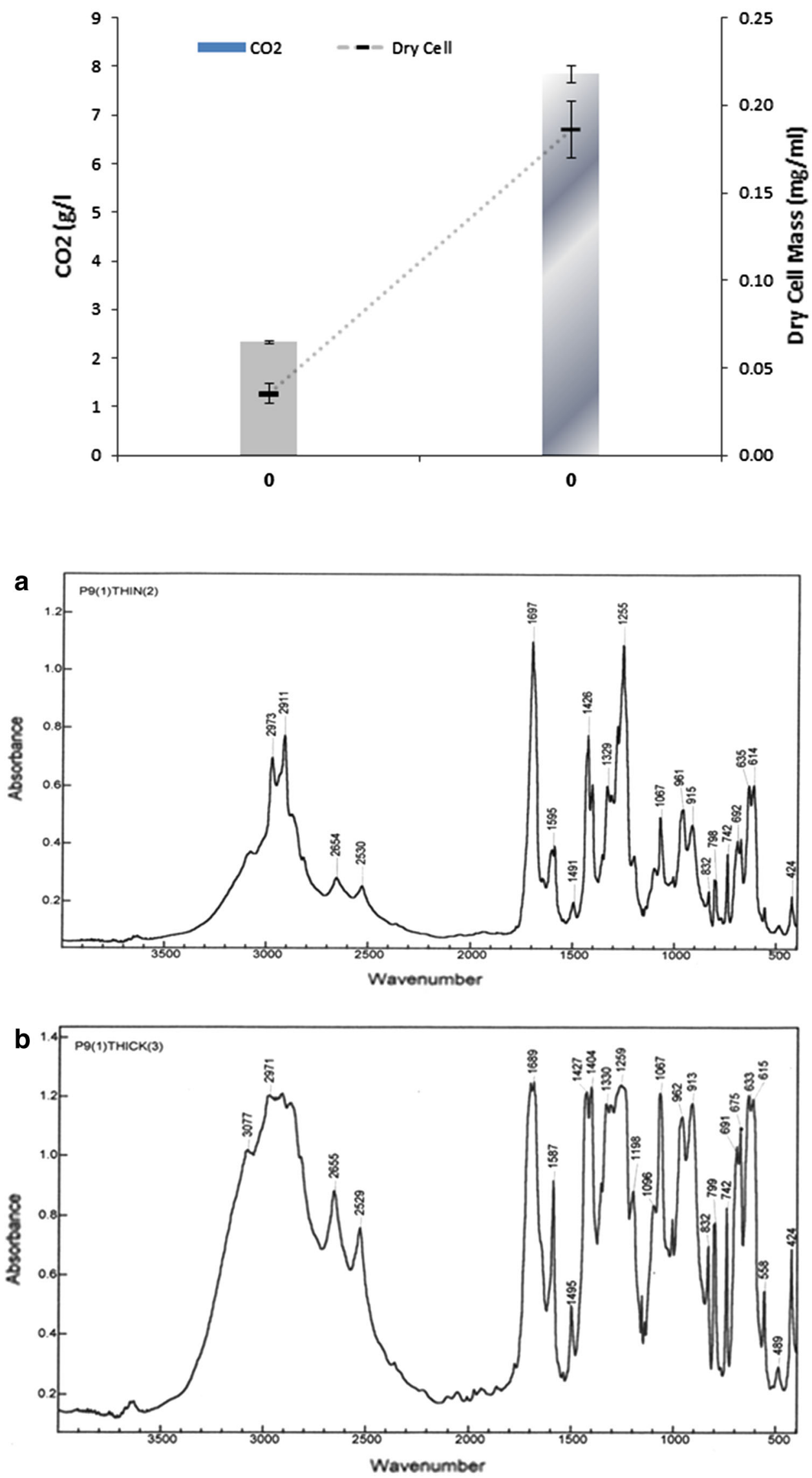
Fig. 6 Gel permeation chromatography analysis of the starch blended polyvinyl chloride films treated with Phanerochaete chrysosporium PV1

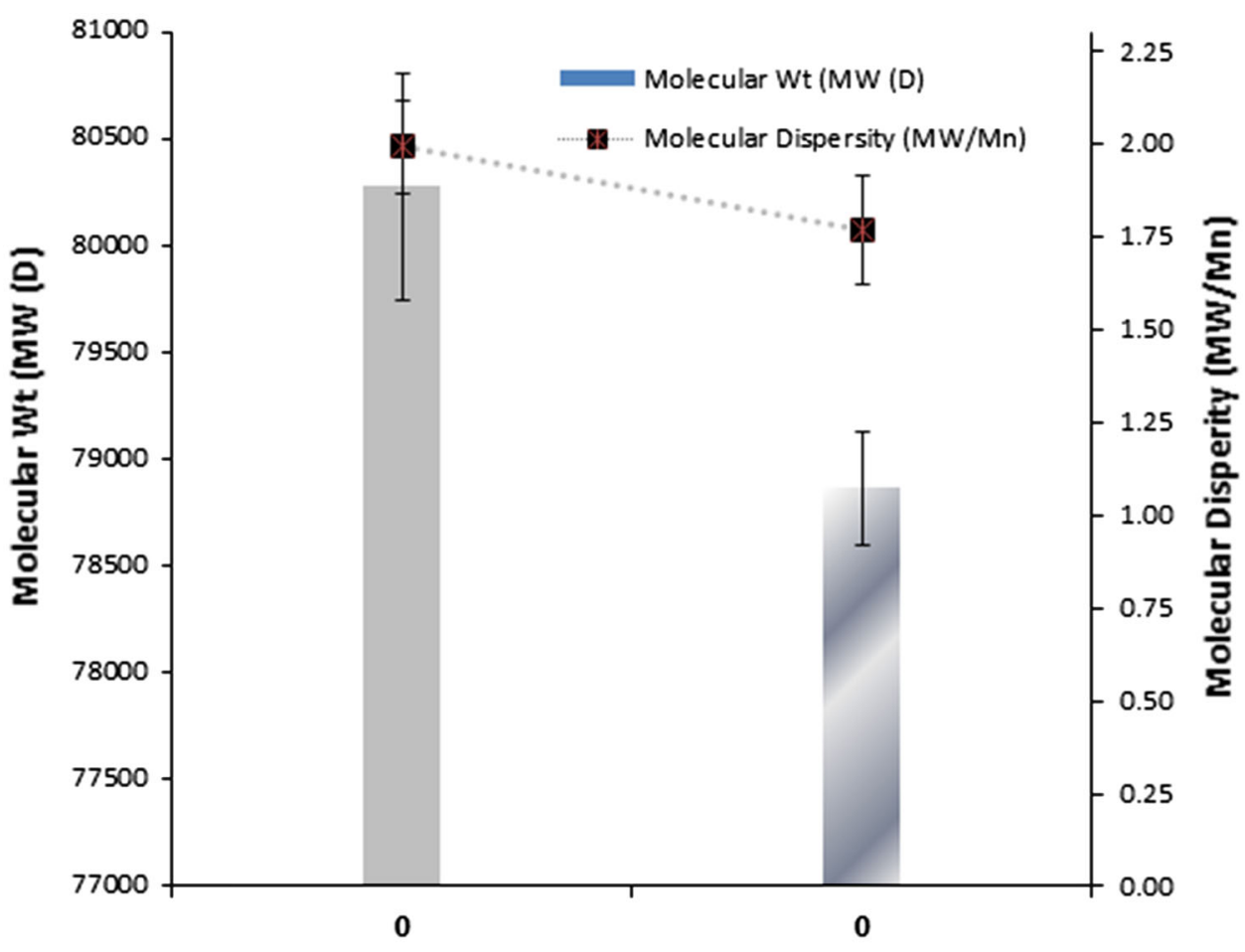

In this test, production of $\mathrm{CO}_{2}$ is mainly taken as indicator of polymer biodegradation in a medium devoid of any additional carbon source (Muller et al. 1992). During Sturm test which was carried out for 30 days, the total production of $\mathrm{CO}_{2}$ with the PVC starch blend film was $7.85 \mathrm{~g} / \mathrm{l}$, whereas it was $2.32 \mathrm{~g} / \mathrm{l}$ in the control (without plastic) in MSM medium with no carbon source (Fig. 4). The production of $\mathrm{CO}_{2}$ in the control treatment is basically linked with oxidative respiration. Moreover, it was significantly related with growth of the $P$. chrysosporium PV1 which was higher in the experimental compared to control flask where no carbon source was employed in the test. The production of $\mathrm{CO}_{2}$ clearly indicated biodegradation activity within the PVC film. Comparatively, the production of higher dry biomass, i.e. of $P$. chrysosporium PV1, was also higher than control $(0.035 \mathrm{mg} / \mathrm{ml})$ (Fig. 4) (Shah et al. 2008a, b).

\section{Analysis by FTIR}

FTIR spectra of polyvinyl chloride recorded in Absorbance mode. The decrease in intensity of the peak at $2,911 \mathrm{~cm}^{-1}$ (corresponding to alkanes $\mathrm{C}-\mathrm{H}$ stretching for $\mathrm{PVC}$ ) and appearance of new peak at $3,077 \mathrm{~cm}^{-1}$ (corresponding to alkenes $=\mathrm{C}-\mathrm{H}$ stretch for PVC) observed in the treated films, confirming the change in the molecular structure of the PVC, also the absorbance of peaks at 2,655-2,529 $\mathrm{cm}^{-1}$ considerably decreased. A shifting and decrease in the sharpness of the peak $1,259 \mathrm{~cm}^{-1}$ (attributed to $\mathrm{C}-\mathrm{H}$ ) observed in treated film. The increase in the sharpness of the peaks also observed in $850-550 \mathrm{~cm}^{-1}$ (attributed to $\mathrm{C}-\mathrm{Cl}$ for PVC) and $1,330 \mathrm{~cm}^{-1}\left(\mathrm{CH}_{2}\right.$ deformation mode) (Marcilla et al. 2008). In addition, a sharp peak appeared at $1,587 \mathrm{~cm}^{-1}$ which was absent in the control treatment (Fig. 5). A substantial reduction in intensity of the carbonyl peak occurring at $1,697 \mathrm{~cm}^{-1}$ indicates the degradation of surface starch, which is previously reported (Dave et al. 1997). According to Kaczmarek and Bajer (2007), the intensity of bands present in the spectra decreases, and also the band at $1,430 \mathrm{~cm}^{-1}(\mathrm{C}-\mathrm{H}$ deformation mode) was absent in DOP which is an evidence of surface decomposition. There were some changes in FTIR spectra of cellulose blended PVC films, a peak at 1,956 and $2,358 \mathrm{~cm}^{-1}$ (corresponding to $\mathrm{O}-\mathrm{H}$ ) disappeared in the treated sample and a new peak appeared at $3,361 \mathrm{~cm}^{-1}$ compared to control (Volke-Sepulveda et al. 2002; Ali et al. 2009; Atiq et al. 2010). These changes in our results clearly indicated a significant transformation in the structure of the PVC blended films due to fungal degradation activity.

\section{Analysis by GPC}

The GPC results indicated that isolated fungal strain $P$. chrysosporium PV1 inflicted maximum decrease in the molecular weight (Mw) of starch blended PVC film $(78,866 \mathrm{Da})$ than the untreated control $(80,275 \mathrm{Da})$. The molecular dispersity (1.731) was also decreased in treated samples as compared to control (untreated starch 
a

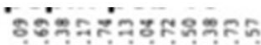

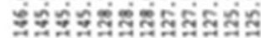
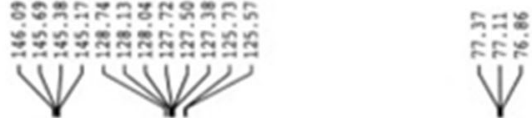

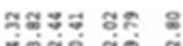

ษสํำ สี่

V
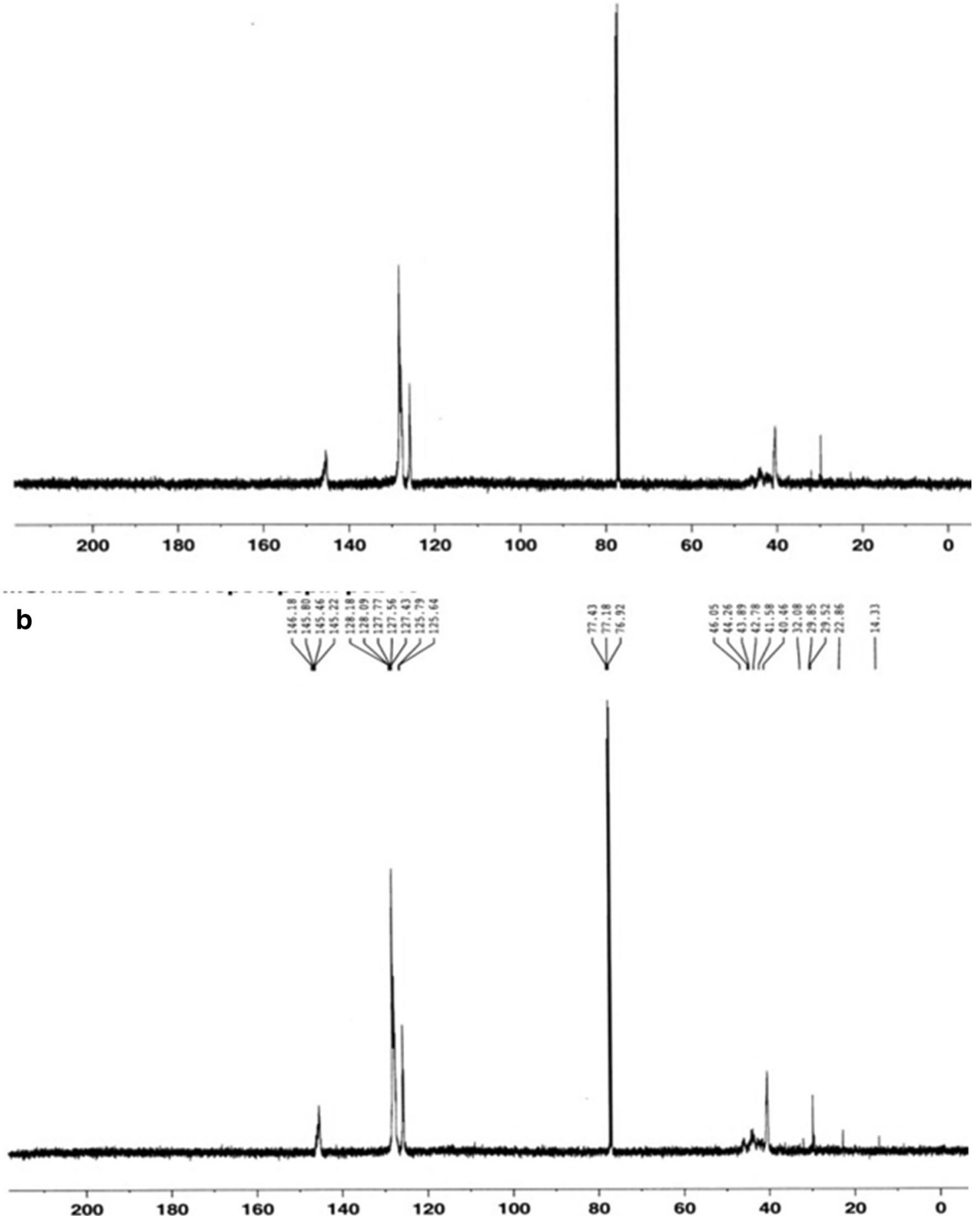

Fig. $7{ }^{\mathrm{C}}$ NMR spectra of the starch blended polyvinyl chloride. a Control, b films treated with Phanerochaete chrysosporium PV1

blended PVC film) (1.991) (Fig. 6). It has been reported that the degradation of PVC by the chain scission reaction and by cross linking resulted either a decrease or increase in its molecular weight (Torikai and Hasegawa 1999). GPC results confirmed randomized degradation of PVC as earlier reported (Andrea et al. 2002). 

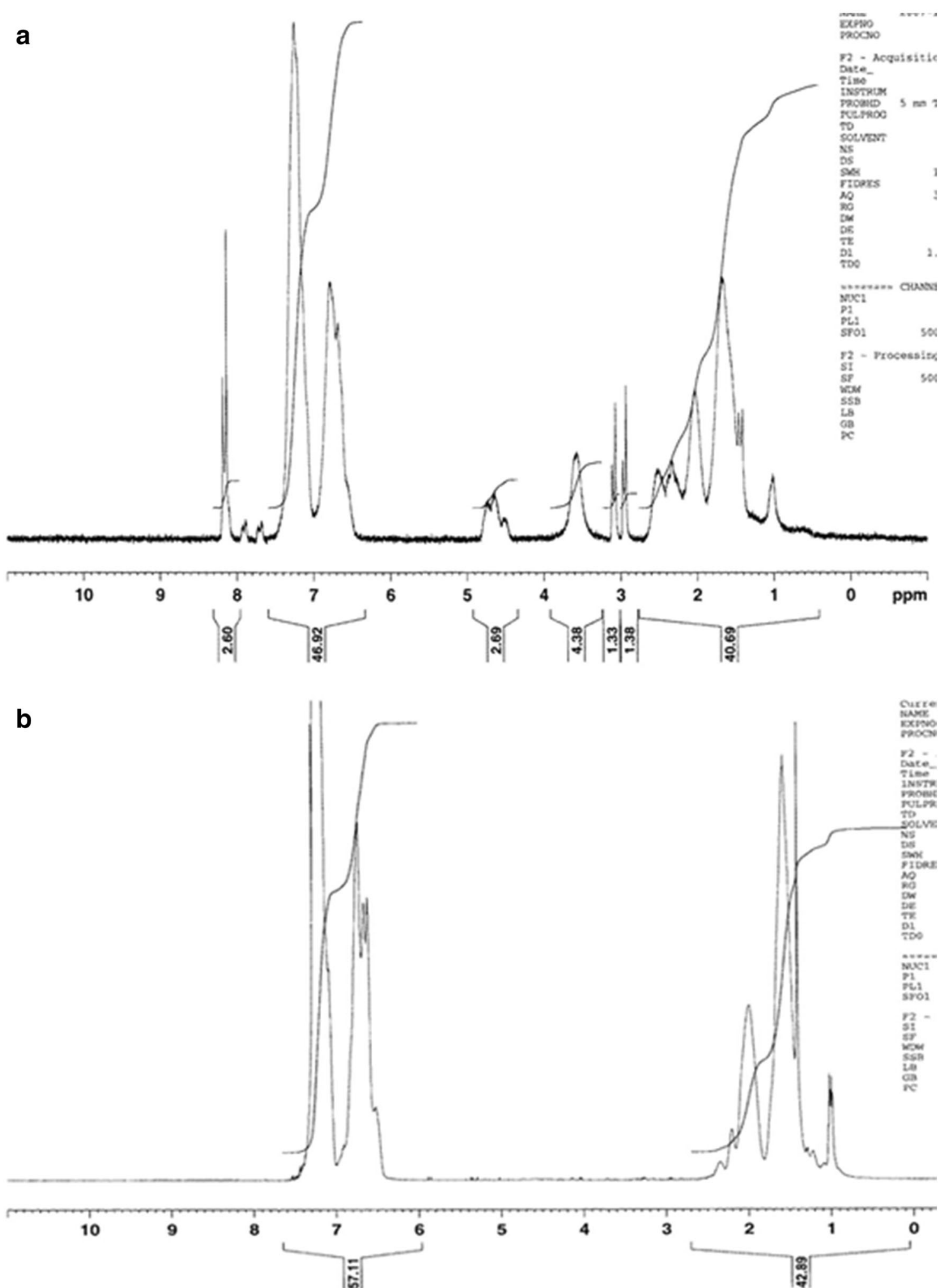

Fig. 8 Proton nuclear magnetic resonance $\left({ }^{1} \mathrm{H}\right.$ NMR) spectra of starch blended polyvinyl chloride, a Control, b treated with Phanerochaete chrysosporium PV1 
Kaczmarek and Bajer (2007) also reported the weight loss of cellulose blended PVC films through GPC due to biodegradation activity.

\section{Analysis by NMR}

Comparing the ${ }^{13} \mathrm{C}$ NMR spectra of the control sample of the starch blended PVC film and treated sample of the starch blended PVC film during shake flask experiments with $P$. chrysosporium PV1 clearly showed a chemical shifting and appearance of the new peak signals 29.85, 41.58, and 46.05 ppm (Fig. 7). A significant increase in the intensity of resonances centered observed; moreover, the major peak of PVC $29.79 \mathrm{ppm}\left(\mathrm{CH}_{2}\right) \mathrm{n}$ has decreased and resulted in more smallest chain fragment. However, the ${ }^{13} \mathrm{C}$ NMR spectra did not show any signals for starch component, reflecting that it is a surface filler and not detected in the ${ }^{13} \mathrm{C}$ spectra as earlier reported (Tikuisis et al. 1993). That effect was more pronounced in the treated starch blended PVC film confirming the biodegradability of the polymer films (Fig. 8). Hoshino et al. (2002) also reported decrease in the intensity and chemical shifting of the signals/peaks in molecular structure of biodegradable plastics during degradation in soils by NMR.

The proton NMR spectra of PVC starch blends also showed the change in the polymer structure due to biodegradation. The signal region for aliphatic protons $\left(-\mathrm{CH}_{2}-\mathrm{CH}-\mathrm{Cl}\right)$ for $\left(-\mathrm{CH}_{2}-\mathrm{CH}-\mathrm{Cl}\right)$ was $1.0-5.0 \mathrm{ppm}$. The total integration of the region for the control sample 0.3-3.1 ppm was $40.69 \mathrm{ppm}$, while for the treated sample integration was increased to 42.89 in the same region. That increase in integration also confirmed the change due to fungal degradation. That increase in integration clearly indicated that during the process, some of the protons have been exhausted as earlier reported (Llauro-Darricades et al. 1989; Hoshino et al. 2002).

\section{Conclusion}

The fungal strain $P$. chrysosporium PV1 showing adherence on the starch blended PVC film surface was able, in adequate conditions, to not only change the polymer surface from smoother to rougher, but also to disrupt the starch blended PVC films. Blending of polymer with additives generally enhances auto-oxidation, reduces the molecular weight of the polymer and makes it easier for microorganisms to degrade the low molecular weight materials The analytical tools like SEM, GPC, FTIR and NMR proved to be important in explaining very small alterations (surface change, decrease in molecular weight and change in chemical structure) involved during the biodegradability of the synthetic polymer. Our better understanding on the biodegradability of the plastics will contribute towards efficient plastic waste treatment.

Acknowledgments The support of Higher Education commission of Pakistan for funding the current research project under Indigenous $\mathrm{PhD}$ fellowship and International Research Support Initiative Program at University of Manchester, United Kingdom is highly appreciated.

\section{References}

Ali MI, Perveen Q, Ahmad B, Javed I, Hussnain R, Andleeb S, Atique N, Ghumro PB, Ahmed S, Hameed A (2009) Studies on biodegradation of cellulose blended polyvinyl chloride films. Int J Agric Biol 11(5):577-580

Ali MI, Ahmed S, Robson G, Javed I, Ali N, Atiq N, Hameed A (2012) Isolation and molecular characterization of polyvinyl chloride (PVC) plastic degrading fungal isolates. J Basic Microbiol. doi:1002/jobm.201200496

Andrea C, Roberto S, Chiellini E (2002) Biodegradation of poly (vinyl alcohol) in selected mixed microbial culture and relevant culture filtrate. Polym Degrad Stab 75:447-458

Atiq N, Ahmed S, Ali MI, Andleeb S, Ahmad B, Robson G (2010) Isolation and identification of polystyrene biodegrading bacteria from soil. Afr J Microbiol Res 4(14):1527-1541

Barratt SR, Ennos AR, Greenhalgh M, Robson GD, Handley PS (2003) Fungi are the predominant micro-organisms responsible for degradation of soil-buried polyester polyurethane over a range of soil water holding capacities. J Appl Microbiol 95: $78-85$

Bikiaris D, Aburto J, Alric I, Borredon E, Botev M, Betchev C, Anayiotou CJ (1999) Mechanical properties and biodegradability of LDPE blends with fatty-acid esters of amylose and starch. Appl Polym Sci 71:1089-1999

Calil MR, Gaboardi F, Guedes CGF, Rosa DS (2006) Comparison of the biodegradation of poly ( $\varepsilon$-caprolactone) cellulose acetate and their blends by the Sturm test and selected cultured fungi. Polym Test 25:597-604

Christensen GD, Baldassarri L, Simpson WA (1995) Methods for studying microbial colonization of plastics. Methods Enzymol 253:477-500

Dave H, Rao PVC, Desai JD (1997) Biodegradation of starch polyethylene films in soil and by microbial cultures. World $\mathrm{J}$ Microbiol Biotechnol 13:655-658

de Campos A, Marconato JC, Franchetti MSM (2011) Biodegradation of blend films PVA/PVC, PVA/PCL in soil and soil with landfill leachate. Braz Arch Biol Technol 54(6):1367-1378

Deguchi T, Kakezawa M, Nishida T (1997) Nylon biodegradation by lignin-degrading fungi. Appl Environ Microbiol 63:329-331

Fanta GF, Swanson CL, Shorgren RL (1992) Starch-poly (ethyleneco-acrylic acid) Composite films. Effects of processing condition on morphology and properties. J Appl Polym Sci 44:20372042

Gu JD, Ford TE, Mitton DB, Mitchell R (2000) Microbial degradation and deterioration of polymeric materials. In: Revie W (ed) The Uhlig corrosion handbook, 2nd edn. Wiley, New York, pp 439-460

Gumargalieva KZ, Zaikov GE, Semenov SA, Zhdanova OA (1999) The influence of biodegradation on the loss of a plasticiser from poly (vinyl chloride). Polym Degrad Stab 63:111-112

Hoshino A, Tsuji M, Fukuda K, Nonagase M, Sawada H, Kimura M (2002) Changes in molecular structure of biodegradable plastics during degradation in soils estimated by FT-IR and NMR. Soil Sci Plant Nutr 48(4):469-473 
Imam SH, Gordon SH, Shogren RL, Greene RV (1995) Biodegradation of starch-poly( $\beta$-hydroxybutyrate-co-valerate) composites in municipal activated sludge. $J$ Environ Polym Degrad 3:205-213

Kaczmarek H, Bajer K (2007) Biodegradation of plasticized poly (vinyl chloride) containing cellulose. Polym Sci 45:903-919

Kay MJ, Morton LHG, Prince EL (1991) Bacterial degradation of polyester polyurethane. Int Biodeter Biodegr 27:205-222

Kirbas Z, Keskin N, Guner A (1999) Biodegradation of polyvinylchloride (PVC) by white-rot fungi. Bull Environ Contam Toxicol 63:335-342

Llauro-Darricades MF, Bensemra N, Guyot A, Pétiaud R (1989) ${ }^{13} \mathrm{C}$ and ${ }^{1} \mathrm{H}$ NMR analysis of structural defects in PVC: application to the production of defects at various polymerization stages. Macromol Chem Macromol Symp 29:171-184

Marcilla A, Garcia S, Garcia-Quesada JC (2008) Migrability of PVC plasticizers. Polym Test 27(2):221-233

Mergaert J, Schirmer A, Hauben L, Mau M, Hoste B, Kersters K, Jendrossek D, Swings J (1996) Isolation and identification of poly(3-hydroxyvalerate) degrading strains of Pseudomonas lemoignei. Int J Syst Bacteriol 46(3):769-773

Muller RJ, Augusta J, Pantke M (1992) An interlaboratory investigation into biodegradation of plastics; Part I: A modified Sturmtest. Material und organismen 27:179-189

Nair MNR, Biju PK, George V, Thomas MR, Nair G (2009) Blends of PVC and epoxidized liquid natural rubber: studies on impact modification. J Appl Polym Sci 111:48-56

Ohtaki A, Sato N, Nakasaki K (1998) Biodegradation of polycaprolactone under controlled composting conditions. Polym Degrad Stab 61(3):499-505

Sabev HA, Handley PS, Robson GD (2006) Fungal colonization of soil-buried plasticized polyvinyl chloride (pPVC) and the impact of incorporated biocides. Microbiol 152:1731-1739

Shah AA, Hasan F, Akhtar JI, Hameed A, Ahmed S (2008a) Degradation of polyurethane by a novel bacterium consortium isolated from soil. Ann Microbiol 58(3):381-386

Shah A, Hameed A, Hasan F, Ahmed S (2008b) Biological degradation of plastics: a comprehensive rev. Biotechnol Adv 26:246-265
Tikuisis T, Axelson DE, Sharma A (1993) Nondestructive quantitative determination of starch content in polyethylene by solid state NMR and FTIR. Polym Eng Sci 33:26-31

Torikai A, Hasegawa H (1999) Accelerated photodegradation of poly(vinyl chloride). Polym Degrad Stab 63:441-445

Tudorachi N, Cascaval CN, Rusu M, Pruteanu M (2000) Testing of polyvinyl alcohol and starch mixtures as biodegradable polymeric materials. Polym Test 19:785-799

Tuominen J, Kylma J, Kapanen A, Venelampi O, Itavaara M, Seppala J (2002) Biodegradation of lactic acid based polymers under controlled composting conditions and evaluation of the ecotoxicological impact. Bio macromolecules 3:445-455

United Nations Environment Programme (2009) Converting waste plastics into a resource. http://www.unep.or.jp/Ietc/Publications/ spc/WastePlasticsEST_AssessmentGuidelines.pdf. Accessed 06 Jan 2012

Upsher FJ, Roseblade RJ (1984) Assessment by tropical exposure of some fungicides in plasticized PVC. Int Biodeterior 20(4): $243-252$

US EPA (2005) Municipal solid waste. United States Environmental Protection Agency. http://www.epa.gov/epaoswer/nonhw/muncpl/ facts.htm). Accessed 12 Mar 2009

Volke-Sepulveda T, Saucedo-Castaneda G, Gutierrez-Rojas M, Manzur A, Favela- Torres E (2002) Thermally treated low density polyethylene biodegradation by Penicillium pinophilum and Aspergillus niger. J Appl Polym Sci 83:305-314

Webb JS, Van der Mei HC, Nixon M, Eastwood IM, Greenhalgh M, Read SJ, Robson GD, Handley PS (1999) Plasticizers increase adhesion of the deteriogenic fungus Aureobasidium pullulans to polyvinylchloride. Appl Environ Microbiol 65:3575-3581

Webb JS, Nixon MI, Eastwood M, Greenhalgh M, Robson GD, Handley PS (2000) Fungal colonization and biodeterioration of plasticized polyvinyl chloride. Appl Environ Microbiol 66: 3194-3200

Wojciechowska P (2012) The Effect of concentration and type of plasticizer on the mechanical properties of cellulose acetate butyrate organic-inorganic hybrids. Recent Advances in Plasticizers. ISBN: 978-953-51-0363-9 Hard cover. InTech, Rijeka 